\title{
ANÁLISE DA PERSISTÊNCIA DO LUCRO DIANTE DOS ACCRUALS DISCRICIONÁRIOS: UM ESTUDO COM BASE NO IMPACTO DA ADOÇÃO DAS IFRS
}

\author{
ANALYSIS OF THE PROFIT PERSISTENCE UNDER THE \\ DISCRETIONARY ACCRUALS: A STUDY BASED ON THE \\ IMPACT OF ADOPTING IFRS
}

\author{
ANÁLISIS DE LA PERSISTENCIA DEL LUCRO ANTE LOS \\ ACCRUALS DISCRICIONARIOS: UN ESTUDIO CON BASE EN EL \\ IMPACTO DE LA ADOPCIÓN DE LAS IFRS
}

Ronan Reis Marçal

Mestre em Ciências Contábeis pela UFRJ e Bacharel em Ciências Contábeis pelo Centro Universitário Carioca (UNICARIOCA)

m.ronanreis@gmail.com

\section{Marcelo Alvaro da Silva Macedo}

Professor de Contabilidade na Universidade Federal do Rio de Janeiro

Pós-Doutor em Controladoria e Contabilidade pela FEA-USP (2010)

Doutor em Engenharia de Produção pela COPPEUFRJ (2006)

malvaro@facc.ufrj.br
Contextus

ISSNe 2178-9258

Organização: Comitê Científico Interinstitucional Editor-Chefe: Diego de Queiroz Machado Editora Associada: Alane Siqueira Rocha Avaliação: double blind review pelo SEER/OJS Recebido em 27/02/2019 Aceito em 08/07/2019 Versão final em 29/05/2019 http://dx.doi.org/10.19094/contextus.v17i2.40706

\section{RESUMO}

A diferença entre o fluxo de caixa e o resultado do exercício chama-se accrual. Esta medida divide-se em uma parcela discricionária, proxy de gerenciamento de resultados, e outra não discricionária, natural das atividades operacionais. A implementação das normas internacionais de contabilidade (IFRS) gerou potencial de mudanças no volume da parcela discricionária. Dela espera-se um prejuízo na persistência dos lucros dado seu caráter arbitrário. Portanto, este estudo analisou o impacto dos accruals discricionários na persistência dos lucros das empresas da B3, considerando a adoção das IFRS. Diante de uma estimação com dados em painel de 100 diferentes empresas, há indícios contrários à lógica de deterioração da persistência pelos accruals discricionários. A explicação reside no gerenciamento de resultados não oportunísticos, que auxilia investidores na tomada de decisão. Ademais, a adoção das IFRS não implica reflexos na relação das acumulações discricionárias com a persistência dos lucros, diferentemente do esperado conforme estudos anteriores.

Palavras-chave: accruals discricionários; persistência dos lucros; gerenciamento de resultados; IFRS.

\begin{abstract}
The difference between cash flow and net profit is called accrual. This measure is divided into a discretionary portion, a proxy for earnings management, and another non-discretionary, natural of the operational activities. The implementation of international accounting standards (IFRS) changed the potential volume of the discretionary portion. From it is expected a loss in the profits persistence given its arbitrary character. Therefore, this study analyzed the impact of discretionary accruals on the profits persistence of B3 companies, considering the adoption of IFRS. Given an estimation with panel data of 100 different companies, there are indications contrary to the logic of deterioration of persistence by discretionary accruals. The explanation lies in nonopportunistic earnings management, which assists investors in decision-making. In addition, the adoption of IFRS does not imply a reflection on the relation between discretionary accumulations and the profits persistence, differently from that expected in previous studies.
\end{abstract}

Keywords: discretionary accruals; profits persistence; earnings management; IFRS. 


\section{RESUMEN}

La diferencia entre el flujo de caja y el resultado del ejercicio se llama accrual. Esta medida se divide en una parcela discrecional, proxy de gestión de resultados, y otra no discrecional, natural de las actividades operativas. La implementación de las normas internacionales de contabilidad (IFRS) generó potencial de cambios en el volumen de la parcela discrecional de esa medida. De ella se espera un perjuicio en la persistencia de los beneficios dado su carácter arbitrario. Por lo tanto, este estudio analizó el impacto de los accruals discrecionales en la persistencia de los beneficios de las empresas de B3, considerando la adopción de las IFRS. Ante una estimación con datos en panel de 100 diferentes empresas, hay indicios contrarios a la lógica de deterioro de la persistencia por los accruals discrecionales. La explicación reside en la gestión de resultados no oportunistas, que auxilia a inversores en la toma de decisión. Además, la adopción de las IFRS no implica reflejos en la relación de las acumulaciones discrecionales con la persistencia de los beneficios, a diferencia de lo esperado según estudios anteriores.

Palabras clave: accruals discrecionales; persistencia de los beneficios; gestión de resultados; IFRS.

\section{INTRODUÇÃO}

\section{A Estrutura Conceitual para Relatórios Financeiros (The Conceptual Framework for} Financial Reporting), disposta pelo International Accounting Standards Board - IASB, define que os relatórios financeiros devem prover usuários externos de informações úteis acerca da entidade que os reporta, fornecendo-lhes a capacidade de tomar as melhores decisões sobre a compra, venda ou manutenção de suas posições financeiras diante da entidade.

Assim, cabem aos demonstrativos disponibilizados pela contabilidade o dever de gerar condições de análises de performance da empresa para seus investidores em quesitos como previsibilidade das disponibilidades, condições de solvência, composição da estrutura de capital (PALEPU; HEALY; BERNARD, 2004).

Khotari (2001) afirma que o resultado corrente das empresas é uma importante ferramenta para a devida avaliação dessas, porém, essa informação não é a única relevante. Esse fato é corroborado por Takamatsu e Fávero (2013) ao explicarem que os usuários externos têm uma tendência de preterir diversas informações contábeis divulgadas em demonstrativos financeiros, valendo-se apenas dos lucros como referência.

No estudo feito por Dichev et al. (2013), 169 diretores financeiros de empresas norteamericanas de capital aberto foram questionados sobre a importância do lucro para diferentes partes interessadas, tais como clientes, fornecedores e empregados. Os resultados da pesquisa indicam que aproximadamente $94 \%$ dos respondentes classificam o lucro como muito importante para os investidores na avaliação das empresas, sendo esses investidores, de acordo com a pesquisa, os maiores beneficiados por parte dessa informação. 
Assim, se o lucro é uma informação importante para a análise feita por investidores, é natural que a manutenção e a consistência desse lucro sejam benéficas para esses usuários para fins de avaliação do valor de mercado da entidade (KOLOZSVARI; MACEDO, 2016).

Quando lucros defasados permitem estimar os lucros correntes de uma empresa, dá-se o nome de persistência dos lucros para tal característica, conforme Dechow, Ge e Schrand (2010). Essa característica, segundo as autoras, seria uma qualidade da informação reportada aos usuários baseada na assunção de que isso melhora a capacidade de avaliação das firmas.

Corroborando tal afirmação, Paulo, Cavalcante e Melo (2012) explicam que o interesse pela persistência dos lucros reside na sua capacidade de previsão dos futuros resultados e, consequentemente, na sua utilização como ferramenta de avaliação dos ativos. Porém, os autores alertam para o fato de que mensurações indevidas dos resultados reduzem a persistência dos lucros, culminando em perda da utilidade da informação.

A persistência dos lucros é uma condição determinante na qualidade dos lucros se, e somente se, os resultados representarem com fidedignidade o desempenho da firma durante o período e se o desempenho atual for persistente no futuro (DECHOW; SCHRAND, 2004).

Em respeito ao regime de competência, a Ciência Contábil quase sempre irá apresentar resultados financeiros e resultados econômicos distintos. As diferenças entre o lucro baseado no regime de competência e o resultado exclusivamente financeiro recebem o nome de accruals, assim, tem-se que o lucro é formado por dois componentes, quais sejam: fluxos de caixa e accruals, ou acumulações (ALMEIDA, 2010).

O objetivo do registro dessa medida é apresentar o resultado econômico, demonstrando o efetivo aumento de riqueza da entidade, independentemente da movimentação financeira. Todavia, embora os accruals possam ajudar nas práticas de avaliação de ativos, quando gestores modificam arbitrariamente essas medidas com o intuito de gerar reflexos nos lucros, elas se tornam uma proxy de gerenciamento de resultados (MARTINEZ, 2008).

Destarte, conforme Martinez (2008), as acumulações podem ser divididas em dois subgrupos: 1) discricionárias, que representam a parcela referente a escolhas contábeis arbitrárias que podem incluir medidas de gerenciamento de resultados e; 2) não discricionárias, referentes ao restante do total de acumulações e naturais das atividades da empresa, não estando atreladas à ações com o propósito de gerenciar os resultados da empresa. 
Paralelo a isso, é importante destacar que o cenário contábil no Brasil passou por grandes mutações desde o processo de convergência ao padrão International Financial Reporting Standards (IFRS), implementado pela Lei $\mathrm{n}^{\circ}$ 11.638/07. Alguns estudos evidenciaram essa questão em termos comparativos, a exemplo de Fé Júnior, Nakao e Ribeiro (2015), que identificaram uma melhoria na informação destinada aos investidores de bancos brasileiros de capital aberto quando estes fizeram sua primeira divulgação no padrão IFRS.

Com a adoção das IFRS, as acumulações discricionárias obtiveram reflexos em seus montantes, sendo diagnosticados casos de aumento, como nos trabalhos de Cardoso, Souza e Dantas (2015) e Boina e Macedo (2018), e também casos de redução, como nos trabalhos de Grecco et al. (2014) e Joia e Nakao (2014).

Considerando isso e o fato de que os accruals discricionários podem estar atrelados ao gerenciamento de resultados, é importante que novas pesquisas sejam feitas considerando o efeito comparativo entre os períodos pré-IFRS e pós-IFRS em relação a essa medida. Essa lacuna foi ressaltada, inclusive, por Cardoso, Souza e Dantas (2015).

Assim, destacada a relevância do lucro perante usuários externos; a vantagem informacional para esses usuários quando esses lucros são persistentes; a possibilidade de interferência nos lucros divulgados diante de atitudes arbitrárias dos gestores, representadas nesse estudo pelos accruals discricionários; bem como a mutação dessa medida após a adoção do padrão contábil IFRS, surge o seguinte problema de pesquisa: qual o impacto dos accruals discricionários na persistência dos lucros de empresas listadas no mercado brasileiro de capitais, considerando o efeito da adoção das IFRS?

Para responder tal problema, o lucro defasado foi decomposto em suas parcelas de fluxos de caixa, accruals não discricionários e discricionários. Especificamente em relação à parcela discricionária, se esta não consegue explicar o lucro presente, tem-se que o gerenciamento de resultado tem impacto negativo, reduzindo a persistência do lucro.

Desta maneira, o objetivo primário desta pesquisa foi analisar o impacto dos accruals discricionários na condição de persistência dos lucros, considerando a adoção das IFRS, para as empresas do mercado brasileiro de capitais. Como objetivo secundário, foi analisada a persistência dos lucros perante seus outros componentes, ou seja, os fluxos de caixa e os accruals não discricionários.

Este trabalho se diferencia de trabalhos anteriores, como os de Cupertino (2010), Takamatsu e Fávero (2013), ao analisar o impacto dos accruals discricionários na persistência 
dos lucros, considerando o efeito da adoção das IFRS. A análise das IFRS nessa questão se faz importante à medida que tal adoção implica no volume das acumulações discricionárias, vide Joia e Nakao (2014) e Boina e Macedo (2018). Portanto, os resultados desta pesquisa podem indicar mudanças na comparação dos resultados de pesquisas correlatas em função da alteração do padrão contábil adotado no Brasil.

O presente estudo pode contribuir ao demonstrar a influência da adoção das IFRS no Brasil nas práticas de gerenciamento de resultados via accruals discricionários e seus consequentes reflexos na persistência dos lucros. Assim, será possível compreender se a adoção das IFRS foi benéfica, maléfica ou indiferente para a característica de persistência dos lucros.

\section{REFERENCIAL TEÓRICO}

Esta seção versa sobre: os accruals como medida de gerenciamento de resultados; a sua relação com a adoção das IFRS; conceitos acerca da persistência dos lucros e; por fim, sobre o desenvolvimento das hipóteses de pesquisa.

\subsection{Gerenciamento de Resultados via Accruals}

O conceito de gerenciamento de resultados pode ser explorado diante do exposto de Healy e Wahlen (1999) de que tal fenômeno seria o resultado das medidas arbitrárias dos gestores ao manipularem as informações contábeis divulgadas acerca do desempenho da empresa.

Conforme Hendriksen e Van Breda (2009), os lucros podem ser medidas perigosas para os usuários externos à medida que podem estar distorcidos em função de ações arbitrárias dos gestores dadas algumas condições discricionárias de certas escolhas contábeis.

Destaca-se que nem toda prática de gerenciamento de resultados é dolosa. Sob o prisma da manipulação oportunística, de fato, os gestores tomam medidas visando ludibriar os investidores, contudo, há também a chamada perspectiva informacional, onde os gestores estão apenas demonstrando suas expectativas particulares sobre o futuro da firma (PAULO, 2007). Silva et al. (2018) destacam, por exemplo, que embora a literatura sugira uma manipulação de resultados frequente dos gestores, por meio das operações descontinuadas, 
visando inflar as receitas ou reduzir as despesas, não há evidências de que as empresas brasileiras de capital aberto sigam essa tendência, ou seja, a ação pode simplesmente representar a melhor escolha para a empresa.

Independentemente do propósito, Healy e Wahlen (1999) denotam que quando os gestores alteram as informações divulgadas pela contabilidade diante de algum poder discricionário, estes passam a modificar a percepção dos usuários sobre a real situação econômico-financeira da entidade em questão. Mas para Scott (2003), devido às deficiências na regulação contábil, medidas de gerenciamento de resultados, na perspectiva informacional, seriam até mesmo benéficas aos usuários externos em situações onde serviriam como complemento de uma informação pouco relevante.

No que se refere ao gerenciamento de resultados com propósitos duvidosos, Dichev et al. (2014) entrevistaram profissionais da área financeira do mercado norte-americano e verificaram que os accruals são um dos principais meios de gerenciamento de resultados.

De acordo com Lopes e Martins (2005), a administração dos accruals pelos gestores de fato se caracteriza como um campo no qual há espaço para julgamentos próprios dos gestores e que, em certos momentos, permite ações voltadas a interesses particulares.

Segundo Martinez (2008), o registro de accruals objetiva mensurar o lucro econômico independentemente da movimentação financeira e não há problema algum nesse fato. Todavia, quando gestores modificam arbitrariamente os accruals com o intuito de gerar reflexos fictícios nos lucros, estes se tornam uma proxy de gerenciamento de resultados.

Figura 1 - Accruals discricionários e não discricionários

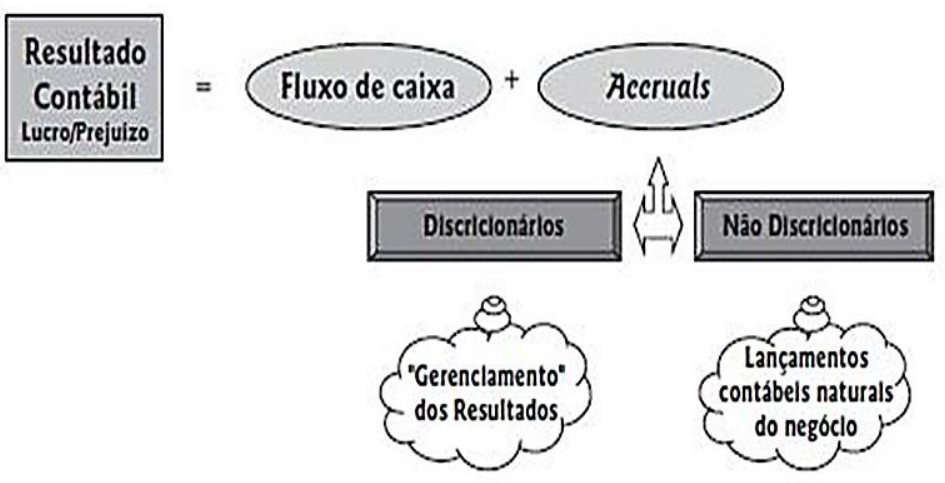

Fonte: adaptado de Martinez (2008, p. 9).

Frente ao que foi exposto na Figura 1, a parcela decorrente de medidas arbitrárias é denominada discricionária, enquanto a parcela não discricionária surge basicamente em 
função do descasamento dos regimes de caixa e competência, não estando atrelada, portanto, a práticas de gerenciamento de resultados.

\subsection{Accruals Discricionários e as IFRS}

A informação de alta qualidade é um dos pilares de eficiência dos mercados. Assim, cabe ao padrão contábil adotado em um determinado local a função de gerar regras que permitam embasar de forma transparente as informações contábeis que serão repassadas aos usuários dos demonstrativos contábeis e financeiros (AHMED; CHALMERS; KHLIF, 2013).

A proposta de adoção das IFRS não foge à essa regra. Conforme Daske (2006), o padrão contábil disponibilizado pelo IASB melhora a informação contábil à medida que exige maiores medidas de transparência e informações a respeito da mensuração de determinados itens, causando um reflexo positivo na qualidade da informação prestada.

Para Chan, Lin e Mo (2010), uma das características das IFRS é oferecer uma maior liberdade aos gestores na escolha de uma determinada política contábil frente a outra, representando melhor a realidade econômica da entidade. Essa maior discricionariedade, contudo, pode ser utilizada como uma via para o aumento de medidas de gerenciamento de resultados, conforme Ahmed, Chalmes e Khlif (2013). Dessa forma, seria natural haver uma tendência de crescimento dos accruals discricionários após aderir às IFRS (BARTH; LANDSMAN; LANG, 2008).

Alguns estudos sustentam a referida argumentação. Por exemplo, no mercado de capitais da Alemanha, durante o período de 1999 a 2001, foi notado o aumento dos accruals discricionários para as empresas que adotaram as IFRS em detrimento do padrão contábil alemão, considerando os resultados de Van Tendeloo e Vanstraelen (2005). No estudo feito por Callao e Jarne (2010) com empresas de 11 diferentes países da União Europeia, também foi verificado o avanço em termos absolutos dos accruals discricionários após a adoção das IFRS.

O estudo de Domingos, Lima e Ponte (2013) identifica, por exemplo, que após a adoção das IFRS, as empresas da B3 passaram a gerenciar resultados por income smoothing (suavização dos resultados) diante de contas como "ajustes de avaliação patrimonial”, dado o caráter subjetivo da avaliação a valor justo de contas deste gênero.

Silva e Silva (2015), similarmente, relatam discrepâncias entre o lucro líquido e o 
resultado abrangente, este último sendo divulgado obrigatoriamente apenas após a adoção das normas internacionais de contabilidade. Eles concluem que os investidores devem se atentar ao analisar as demonstrações contábeis em questão, uma vez que o reconhecimento dos resultados abrangentes no resultado do exercício geraria uma maior volatilidade.

Todavia, há outro entendimento de que a adoção das IFRS acarreta uma menor probabilidade de gerenciamento de resultados. Nessa linha de pensamento, a exigência de informações mais transparentes ao mercado por parte das IFRS reduziria a incidência de tais práticas danosas à qualidade da informação prestada (LEUZ; NANDA; WYSOCKI, 2003).

Essa lógica, que em teoria reduziria os accruals discricionários, também teve resultados atestados em pesquisas anteriores. Prather-Kinsey e Shelton (2005) e Chen et al. (2010) são exemplos disso, valendo-se de amostras representadas por empresas de nações europeias.

No Brasil, Joia e Nakao (2014) e Grecco et al. (2014) identificaram reduções nos accruals discricionários após a adoção das IFRS, ao passo que Cardoso, Souza e Dantas (2015) e Boina e Macedo (2018), detectaram um aumento nessa medida após tal adoção.

\subsection{Persistência dos Lucros}

Para Dichev et al. (2013), os lucros são as informações contábeis mais importantes para os usuários, sendo o conceito de qualidade dos lucros fundamental para os campos da contabilidade e finanças. Contudo, para esses autores e para Kolozsvari e Macedo (2016), não há um consenso na literatura acerca da qualidade do lucro reportado tendo em vista as diversas abordagens existentes, inviabilizando uma determinada classificação como adequada.

Todavia, a persistência dos lucros é preponderantemente apontada como uma das características de qualidade do lucro por muitos autores, a exemplo de Dechow, Ge e Schrand (2010) e Dichev et al. (2013).

A persistência dos lucros foi definida por Lev (1983) como a ocorrência constante dos lucros, ou seja, a não eventualidade deles. Essa característica é vista como um fator positivo na qualidade do lucro contábil a partir da premissa de que lucros não aleatórios são mais úteis para a avaliação das firmas (KOLOZVARI; MACEDO, 2016). Tal característica pode ser mensurada a partir do modelo a seguir, disposto por Dechow, Ge e Schrand (2010): 


$$
L_{t}=\alpha+\beta_{1} \cdot L_{t-1}+\varepsilon
$$

Onde:

$\mathrm{L}_{\mathrm{t}}$ é a medida de lucro adotada no período t;

$\mathrm{L}_{\mathrm{t}-1}$ é a medida de lucro adotada no período t-1;

$\alpha$ é o termo constante;

$\beta$ é o coeficiente angular;

$\varepsilon$ é o termo de erro.

Outro fator determinante para a observação da persistência dos lucros diz respeito aos componentes desses lucros. Ocorre que a exigência do regime de competência pela contabilidade culmina em uma diferença entre o lucro econômico e o fluxo de caixa operacional. Essa diferença, como visto anteriormente, recebe o nome de accrual. Portanto, fica evidenciado que o lucro é composto por duas parcelas: fluxos de caixa e acumulações (KOLOZSVARI; MACEDO, 2016).

Conforme Dechow e Dichev (2002), os fluxos de caixa dizem respeito às receitas e despesas que tiveram seus efeitos financeiros efetivamente ocorridos durante o exercício em questão, ao passo que os accruals ajustam temporariamente os fluxos de caixa alocando-os no período ao qual são reconhecidos contabilmente.

Em igual sentido, Takamatsu e Fávero (2013) explicam que como os accruals são determinados a partir da diferença entre o lucro contábil do período e os fluxos de caixa dele provenientes, quanto mais elevada for a estimativa dos accruals, maior será o descasamento entre o regime de competência e o regime de caixa.

Sloan (1996) verificou as condições de persistência do lucro de forma isolada conforme os dois componentes do lucro e identificou que os accruals prejudicam a característica da persistência de lucros em comparação aos lucros persistentes exclusivamente compostos por fluxos de caixa. A razão exposta pelo autor para tal fenômeno seria de que as acumulações são dotadas de uma grande parcela de subjetividade.

Posteriormente, Dechow e Ge (2006) viriam a complementar o trabalho de Sloan (1996) ao apontar que apenas accruals pequenos reduzem a persistência dos lucros, enquanto valores significativos podem até mesmo melhorar a condição da persistência dos lucros. Isso 
ocorre, segundo as autoras, devido ao fato de que os gestores de empresas cujos accruals são menores estariam possivelmente fazendo ajustes arbitrários visando reavaliar seus ativos líquidos dada uma eventual inexistência de itens especiais.

De acordo com Leal et al. (2017), itens especiais seriam "especiais" por não serem constantes, ocorrendo apenas esporadicamente. Nissim e Penman (2001) e Dichev et al. (2013) também apontam a ausência de itens especiais como um fator determinante na redução da persistência.

\subsection{Desenvolvimento das Hipóteses de Pesquisa}

As hipóteses de pesquisa dizem respeito à possibilidade dos accruals discricionários estarem sendo gerenciados e impactarem a persistência dos lucros, prejudicando a qualidade da informação contábil destinada aos usuários externos em geral.

Healy e Wahlen (1999) destacam que eventuais interesses pessoais relacionados aos mercados de capitais são uma das grandes causas das práticas de gerenciamento de resultados por meio de accruals discricionários. De acordo com Graham, Harvey e Rajgopal (2005), gestores podem vir a manipular resultados nesse sentido, eventualmente, graças à crença de que o mercado não gosta de incertezas e valoriza resultados previsíveis.

Consoante o disposto pela revisão de literatura previamente apresentada e em busca do atendimento aos objetivos propostos para o presente trabalho, foram formuladas as seguintes hipóteses de pesquisa:

H1: Os accruals discricionários do período anterior não conseguem explicar o lucro corrente nas empresas do mercado brasileiro de capitais.

Esta hipótese é sustentada diante do tratamento dos accruals discricionários como proxy de gerenciamento de resultados, vide Healy e Wahlen (1999) e Martinez (2008), por ser essa parcela do lucro arbitrária. Como as medidas de gerenciamento de resultados são danosas à qualidade informacional dos lucros e a persistência dos lucros é uma medida de qualidade dos lucros (DECHOW; GE; SCHRAND, 2010; DICHEV et al., 2013), é natural esperar que as acumulações discricionárias prejudiquem a persistência dos lucros, tendo em vista que essa parcela do lucro pode estar sendo modificada pelos gestores diante de suas escolhas.

E, considerando a possibilidade de mudanças nos volumes de accruals discricionários 
perante a adoção das IFRS, conforme reportado nas pesquisas de Chen et al. (2010), Callao e Jarne (2010), Joia e Nakao (2014), Boina e Macedo (2018), entre outras, é factível crer que o impacto dessa medida na persistência dos lucros seja modificado, portanto:

H2: A adoção das IFRS pelas empresas do mercado brasileiro de capitais influencia o impacto dos accruals discricionários do período anterior na persistência dos lucros.

\section{METODOLOGIA}

Esta pesquisa vale-se de uma abordagem quantitativa, tendo em vista que há uma coleta de dados e posteriores tratamentos e análises destes para a obtenção das futuras conclusões (MARTINS; THEÓPHILO, 2009).

A população da pesquisa diz respeito às empresas não-financeiras listadas na B3 (Bolsa, Brasil, Balcão) durante o intervalo cronológico de 2000 a 2017. Os dados foram coletados diante da base Economática ${ }^{\circledR}$, sendo o período pré-IFRS composto pelos exercícios de 2000 a 2007, e o período pós-IFRS composto pelos exercícios de 2010 a 2017. Os exercícios de 2008 e 2009 não foram aderidos pois, nesse intervalo, a adoção ao padrão IFRS era voluntária, portanto, não seria possível segregar as distintas informações divulgadas ao mercado.

Em relação ao período pós-IFRS, embora os dados sejam coletados a partir de 2010, a utilização das observações em si deu-se a partir de 2012. Isso ocorre pois algumas variáveis utilizadas requerem variações de saldos e ponderações por dados defasados em até 2 anos, portanto, uma coleta em 2011 implicaria necessariamente em informações parciais de 2009, fato que geraria um equívoco nas análises considerando que os padrões contábeis seriam distintos a julgar pela convergência ao padrão internacional disposto pelo IASB em 2010. Seguindo o mesmo parâmetro, o período pré-IFRS teve suas análises feitas a partir de 2002.

A população da pesquisa importava num total de 4384 observações. Todavia, diante da indisponibilidade de ao menos um dos dados necessários para a pesquisa e do interesse no acompanhamento cronológico das empresas, foram eliminadas 3184 observações, restando assim, uma amostra final de 1200 observações referente a 100 diferentes empresas.

Visando analisar a persistência dos lucros, foram coletados dados referentes aos resultados dos exercícios das empresas. Esse tratamento segue o modelo básico de persistência disposto por Dechow, Ge e Schrand (2010), sendo o Earnings Before Interest and 
Taxes (EBIT) a medida utilizada como lucro, muito embora outras medidas de lucro pudessem ser igualmente utilizadas conforme esses autores.

Em um segundo momento, o resultado das empresas foi seccionado em componentes de fluxos de caixa e accruals totais. Isso foi feito por meio da abordagem do Balanço Patrimonial (BP), destacada por Paulo (2007) e disposta a seguir:

$$
A T_{i, t}=\left(\Delta A C_{i, t}-\Delta D I S P_{i, t}\right)-\left(\Delta P C_{i, t}-\Delta P F C P_{i, t}\right)-D E P A M O_{i, t} / A_{i, t-1}
$$

Onde:

$\mathrm{AT}_{\mathrm{i}, \mathrm{t}}$ é o montante de accruals totais da empresa i no período t;

$\mathrm{A}_{\mathrm{i}, \mathrm{t}-1}$ são os ativos totais da empresa i no período t-1;

$\Delta \mathrm{AC}_{\mathrm{i}, \mathrm{t}}$ é a variação do Ativo Circulante da empresa i no período t;

$\Delta \mathrm{PC}_{\mathrm{i}, \mathrm{t}}$ é a variação do Passivo Circulante da empresa i no período $\mathrm{t}$;

$\Delta \mathrm{DISP}_{\mathrm{i}, \mathrm{t}}$ é a variação das Disponibilidades da empresa i no período t;

$\triangle \mathrm{PFCP}_{\mathrm{i}, \mathrm{t}}$ é a variação do Passivo Financeiro de Curto Prazo da empresa i no período t;

DEPAMO $_{i, t}$ são as despesas de depreciação e amortização da empresa i no período t.

A escolha por essa abordagem decorre da inexistência da informação dos fluxos de caixa para o período pré-IFRS, uma vez que a Demonstração dos Fluxos de Caixa (DFC) só passou a ser obrigatória para empresas de capital aberto após a adoção das IFRS. Portanto, foi utilizada a abordagem do BP para estimar os accruals totais em todos os exercícios e, pela diferença do EBIT com essa medida, foram obtidos os fluxos de caixa. Dessa forma, não há o risco de analisar dados cujas estimações sejam distintas.

Por fim, os próprios accruals foram divididos em suas parcelas discricionárias e não discricionárias. Para esse fim foi utilizado o modelo de Jones Modificado (1995):

$$
T A_{i, t} / A_{i, t-1}=\beta_{1}\left(1 / A_{i, t-1}\right)+\beta_{2}\left[\left(\Delta R E V_{i, t}-\Delta A R_{i, t}\right) / A_{i, t-1}\right]+\beta_{3}\left(P P E_{i, t} / A_{i, t-1}\right)+\varepsilon_{i, t}(3)
$$

Onde:

$\mathrm{TA}_{\mathrm{i}, \mathrm{t}}$ são os accruals não totais da empresa i no período t;

$\mathrm{A}_{\mathrm{i}, \mathrm{t}-1}$ são os ativos totais da empresa i no período t-1;

$\triangle \mathrm{REV}_{\mathrm{i}, \mathrm{t}}$ é a variação das receitas da empresa i entre o período t e o período t-1;

$\Delta \mathrm{AR}_{\mathrm{i}, \mathrm{t}}$ é a variação do saldo de contas a receber entre o período t e o período t-1; 
$\mathrm{PPE}_{\mathrm{i}, \mathrm{t}}$ é o saldo das contas do ativo imobilizado da empresa i no período t;

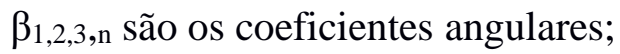

$\varepsilon_{i, t}$ é o termo de erro da empresa i no período t.

Conforme Dechow, Sloan e Sweeney (1995), qualquer modelo de mensuração de accruals discricionários apresenta algum tipo de limitação, porém, considerando a recente pesquisa nacional de Consoni, Colauto e Lima (2017) que indicou o modelo de Jones Modificado como o mais apropriado até os dias atuais, optou-se por tal modelo.

Assim, foi possível estimar os accruals discricionários por meio dos resíduos da regressão (MARTINEZ, 2008). Consequentemente, a parcela não discricionária pôde ser obtida pela diferença entre os accruals totais e a parcela discricionária.

Visando realizar o acompanhamento cronológico das empresas, as regressões propostas foram trabalhadas diante de dados em painel, que de acordo com Gujarati e Porter (2011), permitem verificar o comportamento de cada unidade ao longo do tempo, além de oferecer um maior controle sobre a heterogeneidade e apresentar uma maior eficiência nas estimações.

Assim, foram gerados dois modelos com estimações pelo método dos Mínimos Quadrados Ordinários (MQO). Os modelos estão dispostos no Quadro 1, a seguir:

Quadro 1 - Modelos utilizados para verificar as hipóteses de pesquisa

\begin{tabular}{|c|l|c|}
\hline Modelo & \multicolumn{1}{|c|}{ Função } & \multicolumn{1}{c|}{ Equação } \\
\hline 1 & $\begin{array}{l}\text { Verificação da persistência dos } \\
\text { lucros diante do modelo básico }\end{array}$ & $\mathrm{L}_{\mathrm{t}}=\alpha+\beta_{1} . \mathrm{L}_{\mathrm{t}-1}+\beta_{2} . \mathrm{D}_{\mathrm{IFRS}}+\beta_{3} . \mathrm{D}_{\mathrm{IFRS}} \mathrm{x} \mathrm{L}_{\mathrm{t}-1}+$ \\
$\varepsilon$
\end{tabular}

Fonte: elaboração própria.

Onde:

$L_{t}$ é o Lucro da empresa i no período t;

$\mathrm{FCO}_{\mathrm{t}-1}$ é o Fluxo de Caixa Operacional da empresa i no período t-1;

$\mathrm{ACCD}_{\mathrm{t}-1}$ são os Accruals Discricionários da empresa i no período t-1;

ACCND $_{\mathrm{t}-1}$ são os Accruals Não Discricionários da empresa i no período t-1;

DIFRS é uma variável dummy cuja categoria de referência é a ausência do padrão IFRS;

$\alpha$ é a constante da regressão;

$\beta_{1,2,3, \mathrm{n}}$ são os coeficientes angulares da regressão; 
$\varepsilon$ são os resíduos da regressão.

Em ambos os modelos foram feitas, inicialmente, regressões sem as dummies referentes à adoção das IFRS e, logo em seguida, foram apresentados os resultados com a inclusão dessas variáveis. Isso foi feito com o propósito de analisar como as dummies poderiam estar afetando os coeficientes originais das variáveis independentes.

Com tais modelos foi possível verificar as hipóteses de pesquisa formuladas na seção anterior. Porém, além disso, foram elaborados mais dois modelos, apresentados no Quadro 2 a seguir, como propostas de análises adicionais.

Quadro 2 - Modelos adicionais da pesquisa

\begin{tabular}{|c|c|c|}
\hline Modelo & Função & Equação \\
\hline 3 & $\begin{array}{l}\text { Verificação da influência dos } \\
\text { accruals discricionários negativos } \\
\text { na persistência dos lucros, com ou } \\
\text { sem interação das IFRS }\end{array}$ & $\begin{array}{c}\mathrm{L}_{\mathrm{t}}=\alpha+\beta_{1} \cdot \mathrm{L}_{\mathrm{t}-1}+\beta_{2} . \mathrm{D}_{\mathrm{IFRS}}+\beta_{3} . \mathrm{D}_{\mathrm{IFRS}} \times \mathrm{L}_{\mathrm{t}-1} \\
+\beta_{4} . \mathrm{D}_{\mathrm{ACCDNEG}}+\beta_{5} . \mathrm{D}_{\mathrm{ACCDNEG}} \times \mathrm{L}_{\mathrm{t}-1}+\beta_{6} . \\
\mathrm{D}_{\mathrm{IFRS}} \times \mathrm{D}_{\mathrm{ACCDNEG}}+\beta_{7} . \mathrm{D}_{\mathrm{IFRS}} \times \mathrm{D}_{\mathrm{ACCDNEG}} \mathrm{X} \\
\mathrm{L}_{\mathrm{t}-1}+\varepsilon\end{array}$ \\
\hline 4 & $\begin{array}{l}\text { Verificação da influência dos } \\
\text { accruals discricionários extremos } \\
\text { na persistência dos lucros, com ou } \\
\text { sem interação das IFRS }\end{array}$ & $\begin{array}{c}\mathrm{L}_{\mathrm{t}}=\alpha+\beta_{1} \cdot \mathrm{L}_{\mathrm{t}-1}+\beta_{2} . \mathrm{D}_{\text {IFRS }}+\beta_{3} . \mathrm{D}_{\text {IFRS }} \times \mathrm{L}_{\mathrm{t}-1} \\
+\beta_{4} . \mathrm{D}_{\text {Alto GR }}+\beta_{5} . \mathrm{D}_{\text {Alto GR }} \mathrm{L}_{\mathrm{t}-1}+\beta_{6} . \mathrm{D}_{\text {IFRS }} \\
\quad \times \mathrm{D}_{\text {Alto GR }}+\beta_{7} \text {. } \mathrm{D}_{\text {IFRS }} \times \mathrm{D}_{\text {Alto GR }} \times \mathrm{L}_{\mathrm{t}-1}+\varepsilon\end{array}$ \\
\hline
\end{tabular}

Fonte: elaboração própria.

Onde:

$\mathrm{D}_{\mathrm{ACCDNEG}}$ é uma variável dummy que assume valor 1 para ACCD negativo;

DAlto GR é uma variável dummy que assume valor 1 para ACCD extremos.

O modelo 3 decorre da sugestão feita por Paulo (2007) de que os ACCD negativos são utilizados pelos gestores para reduzir lucros excepcionais de um determinado período, ao passo que os ACCD positivos servem para inflar os resultados que ficaram abaixo das metas esperadas. Dessa forma, esse modelo verifica o impacto dessas diferentes vertentes na persistência dos lucros.

Já para o modelo 4, a proposta foi identificar se os ACCD são capazes de impactar a persistência apenas quando gerenciados de forma extrema. Para tanto, os ACCD foram tratados em suas funções modulares, sendo considerados valores extremos o quartil superior da amostra. Assim, 300 observações foram enquadradas nessa condição.

Cabe destacar que todos os modelos de regressão tiveram suas variáveis, dependentes e independentes, ponderadas pelo ativo total do ano anterior. Dessa forma, o efeito tamanho das empresas foi mitigado. A ponderação dos dados visando a redução de assimetria em 
função do tamanho das empresas já havia sido destacada por Almeida, Lopes e Corrar (2011).

Todas as regressões, bem como seus pressupostos básicos, foram feitas diante do software STATA ${ }^{\circledR}$ sempre a um nível de confiança de $95 \%$. Quanto aos referidos pressupostos, foi verificada a normalidade dos dados e a condição de homocedasticidade dos mesmos diante dos testes Jarque-Bera e Breusch-Pagan, respectivamente, seguindo os ensinamentos de Corrar, Paulo e Dias Filho (2007).

A não normalidade dos resíduos pôde ser relaxada diante do tamanho da amostra e do Teorema do Limite Central. Já a heterocedasticidade foi tratada diante da correção robusta de White (GUJARATI; PORTER, 2011).

Por serem regressões múltiplas, foi verificado também o grau de colinearidade entre as variáveis explicativas. Isso foi feito diante do Fator de Inflação da Variância (FIV). Para Gujarati e Porter (2011), uma forma prática de identificar um alto grau de colinearidade é observar se o FIV de uma variável é maior que 10.

Diante de um painel totalmente balanceado e considerando a utilização da abordagem dos efeitos fixos, foi necessário, ainda, verificar a existência de autocorrelação entre os resíduos da regressão. Conforme Gujarati e Porter (2011), o pressuposto é de que o termo de erro relacionado a uma observação não seja influenciado pelo termo de erro de outra observação.

O teste de Wooldridge é uma ferramenta adequada para a verificação do problema de autocorrelação entre os resíduos, de acordo com Drukker (2003). Na ocorrência do referido problema, a medida de ajuste utilizada foi a análise de agrupamentos (cluster analysis) dos erros-padrão nas unidades identificadoras, sugerida como uma medida corretiva não apenas para essa função, mas também para a heterocedasticidade (ROGERS, 1993; HOECHLE, 2007).

Para o tratamento dos outliers da amostra foi adotado o método de winsorização, que foi apontado por Fávero et al. (2009) como um procedimento adequado para tal função. Nessa pesquisa foram aparados os valores extremos referentes a 5\% da amostra, ou seja, 2,5\% de cada cauda da distribuição, sendo estes valores substituídos pelos valores limites remanescentes.

As variáveis winsorizadas foram o EBIT, os accruals totais e os accruals discricionários. As variáveis FCO e ACCND não foram winsorizadas diretamente pois foram calculadas diante da diferença entre o EBIT e os accruals totais e da diferença entre os 
accruals totais e accruals discricionários, respectivamente.

\section{ANÁLISE E DISCUSSÃO DOS RESULTADOS}

Todos os modelos utilizados na pesquisa violaram os pressupostos de normalidade e homocedasticidade dos resíduos; não violaram a regra prática de Gujarati e Porter (2011) para incidência de grave multicolinearidade; e apresentaram resíduos autocorrelacionados. Em todos os casos de violação dos referidos pressupostos, foram tomadas as medidas corretivas apontadas na metodologia.

Além disso, salvo o modelo de Jones Modificado, todos os modelos restantes valeramse da abordagem dos efeitos fixos de acordo com os testes de Chow, Hausman e Multiplicador de Lagrange de Breusch-Pagan.

No que diz respeito à mensuração dos accruals discricionários pelo modelo de Jones modificado, único modelo a ser tratado de forma empilhada (pooled), os resultados foram:

Tabela 1 - Accruals discricionários via modelo Jones modificado

\section{Painel A}

\begin{tabular}{c|c|c|c|c}
\hline$T A_{i, t} / A_{i, t-1}$ & Coeficiente & Erro Padrão & Razão-t & p-valor \\
\hline$\left(1 / A_{i, t-1}\right)$ & $-459,8286$ & 750,6452 & $-0,61$ & 0,550 \\
\hline$\left(\Delta R E V_{i, t}-\Delta A R_{i, t} / A_{i, t-1}\right)$ & 0,387045 & 0,0228822 & 1,69 & 0,091 \\
\hline$\left(P P E_{i, t} / A_{i, t-1}\right)$ & $-0,1084887$ & 0,0098039 & $-11,07$ & 0,000 \\
\hline
\end{tabular}

\section{Painel B}

\begin{tabular}{c|c|c|c}
\hline $\mathrm{R}^{2}$ & 0,0967 & $\mathrm{~F}$ & 46,06 \\
\hline P-valor (F) & 0,0000 & Jarque-Bera & 0,0000 \\
\hline Breusch-Pagan & 0,0000 & Chow & 0,0551 \\
\hline Hausman & 0,7868 & LM Breusch-Pagan & 0,0559 \\
\hline
\end{tabular}

Fonte: elaboração própria.

Nota-se que o modelo é estatisticamente significativo a $1 \%$ de significância, obtendo um poder de explicação $\left(\mathrm{R}^{2}\right)$ de cerca de $9,6 \%$. Dentre suas variáveis independentes, apenas o terceiro beta apresenta significância estatística, sendo esse resultado correlato à pesquisa de Sincerre et al. (2016). O sinal negativo dessa variável está de acordo com o sinal esperado por Paulo (2007), ao explicar o imobilizado está relacionado ao decréscimo dos resultados diante da apropriação das despesas de depreciação.

Agora, com os accruals discricionários extraídos pelos resíduos do modelo de Jones modificado, são apresentadas as análises dos modelos propostos para esta pesquisa. 
Tabela 2 - Resultados do modelo 1 (sem dummies)

\begin{tabular}{c|c|c|c|c}
\hline \multicolumn{5}{c}{ Painel A } \\
\hline $\mathrm{L}_{\mathrm{t}}$ & Coeficiente & Erro Padrão & Razão-t & p-valor \\
\hline Constante & 0,041584 & 0,0042118 & 9,87 & 0,000 \\
\hline $\mathrm{L}_{\mathrm{t}-1}$ & 0,415653 & 0,0566194 & 7,34 & 0,000 \\
\hline \multicolumn{3}{|c|}{ Painel B } & 53,89 \\
\hline $\mathrm{R}^{2}$ Geral & 0,3873 & $\mathrm{~F}$ & 0,0000 \\
\hline P-valor (F) & 0,0000 & Jarque-Bera & 0,0000 \\
\hline Breusch-Pagan & 0,0000 & Chow & 1,0000 \\
\hline Hausman & 0,0000 & LM Breusch-Pagan & - \\
\hline Wooldridge & 0,0000 & Maior VIF &
\end{tabular}

Fonte: elaboração própria.

Os resultados do modelo 1, sem a presença das dummies de IFRS, indicam a significância do modelo como um todo a um nível de confiança de $99 \%$, apresentando um poder de explicação de cerca de $39 \%$.

A variável referente ao EBIT do ano anterior é estatisticamente significativa a um nível de $1 \%$ de significância e apresenta um coeficiente de aproximadamente 0,41. Assim, tem-se que, em média, o aumento de uma unidade nessa variável implicaria em um aumento de 0,41 unidades no lucro corrente. Dessa forma, fica caracterizada a persistência dos lucros, seguindo a tendência dos resultados de Cupertino (2010) e Takamatsu e Fávero (2013).

Em seguida são apresentados os resultados para o modelo 1 com a inclusão das dummies referentes à adoção das IFRS.

Tabela 3 - Resultados do modelo 1 (com dummies)

\begin{tabular}{c|c|c|c|c}
\hline \multicolumn{5}{c}{ Painel A } \\
\hline $\mathrm{L}_{\mathrm{t}}$ & Coeficiente & Erro Padrão & Razão-t & p-valor \\
\hline Constante & 0,0553826 & 0,0072422 & 7,65 & 0,000 \\
\hline $\mathrm{L}_{\mathrm{t}-1}$ & 0,4227259 & 0,0707149 & 5,98 & 0,000 \\
\hline D IFRS $_{\text {IFR }}$ & $-0,0226544$ & 0,0092933 & $-2,44$ & 0,017 \\
\hline${\text { DIFRS X L } \mathrm{t}_{-1}}^{5}$ Painel B & $-1,13$ & 0,261 \\
\hline $\mathrm{R}^{2}$ Geral & $-0,1095161$ & 0,0968425 & $\mathrm{~F}$ & 37,68 \\
\hline P-valor (F) & 0,3796 & 0,0000 & Jarque-Bera & 0,0000 \\
\hline Breusch-Pagan & 0,0000 & Chow & 0,0000 \\
\hline Hausman & 0,0000 & LM Breusch-Pagan & 1,0000 \\
\hline Wooldridge & 0,0000 & Maior VIF & 2,22 \\
\hline
\end{tabular}

Fonte: elaboração própria.

Após a inclusão das dummies, o modelo continua apresentando significância estatística, vide p-valor (F) 0,0000, e tanto o poder explicativo do modelo como o coeficiente 
da variável $\mathrm{L}_{\mathrm{t}-1}$ seguem praticamente inalterados.

Por outro lado, a variável dummy multiplicativa não é estatisticamente significativa, dado seu p-valor de 0,261. Nesse sentido, é possível inferir que a persistência dos lucros não foi afetada pela convergência ao padrão IFRS.

A indiferença da condição de persistência diante da adoção das IFRS contraria a ideia disposta por Barth, Landsman e Lang (2008) de que seria natural haver uma redução da qualidade do lucro reportado pelas empresas após as IFRS considerando um possível aumento de medidas de gerenciamento de resultados diante da maior liberdade ofertada aos gestores. Assim, esse resultado contraria, também, as pesquisas de Klann e Beuren (2012) e Ahmed, Chalmes e Khlif (2013).

O resultado é contrário também, porém em sentido oposto, aos trabalhos de Leuz, Nanda e Wysocki (2003) e Daske (2006). Segundo estes autores, a adoção das IFRS deveria tornar o lucro uma informação de melhor qualidade, tendo em vista a padronização das informações divulgadas ao mercado e a maior transparência que viriam a reduzir o risco de ocorrência de gerenciamento de resultados.

A recente pesquisa de Kolozsvari e Macedo (2018) é um exemplo disso ao encontrar indícios de que não havia persistência para o período anterior à adoção das IFRS, mas que isso havia se alterado após tal mudança de padrão contábil. O resultado da presente pesquisa vai de encontro a isso, sendo a diferença na composição da amostra uma possível motivação para os distintos resultados, uma vez que, na referida pesquisa, o período analisado foi de 2003 a 2014, incluindo o período voluntário de adoção das IFRS (2008-2009).

Na sequência são apresentados os resultados do modelo 2, com e sem as dummies referentes às IFRS, respectivamente.

Tabela 4 - Resultados do modelo 2 (sem dummies)

Painel A

\begin{tabular}{c|c|c|c|c}
\hline $\mathrm{L}_{\mathrm{t}}$ & Coeficiente & Erro Padrão & Razão-t & p-valor \\
\hline Constante & 0,0443926 & 0,006078 & 7,30 & 0,000 \\
\hline FCO $_{\mathrm{t}-1}$ & 0,4084330 & 0,057559 & 7,10 & 0,000 \\
\hline $\mathrm{ACCND}_{\mathrm{t}-1}$ & 0,4624659 & 0,107235 & 4,31 & 0,000 \\
\hline $\mathrm{ACCD}_{\mathrm{t}-1}$ & 0,4300705 & 0,057739 & 7,35 & 0,000 \\
\hline
\end{tabular}




\section{Painel B}

\begin{tabular}{c|c|c|c}
\hline $\mathrm{R}^{2}$ Geral & 0,3873 & $\mathrm{~F}$ & 18,98 \\
\hline P-valor (F) & 0,0000 & Jarque-Bera & 0,0000 \\
\hline Breusch-Pagan & 0,0000 & Chow & 0,0000 \\
\hline Hausman & 0,0000 & LM Breusch-Pagan & 1,0000 \\
\hline Wooldridge & 0,0000 & Maior VIF & 2,12 \\
\hline
\end{tabular}

Fonte: elaboração própria.

De acordo com a Tabela 4, é possível afirmar que o modelo 2, sem as dummies, é estatisticamente significativo a um nível de confiança de 99\%, dado seu p-valor de 0,0000. Além disso, o modelo como um todo consegue explicar cerca de $39 \%$ da variação dos resultados correntes. Todas as variáveis independentes apresentam significância estatística e sinal positivo na relação linear com os lucros correntes.

O coeficiente positivo de 0,408 da variável FCO é bem próximo ao coeficiente para essa mesma variável nos estudos de Cupertino (2010) e Takamatsu e Fávero (2013), quais sejam, 0,394 e 0,412, respectivamente.

Em relação ao sinal positivo dos accruals não discricionários, tal parcela do lucro defasado contribui para a condição de persistência dos lucros. Portanto, esse resultado está seguindo o que foi disposto por Dechow e Schrand (2004), Martinez (2008) e Paulo, Cavalcante e Melo (2012), de que a parcela não gerenciável dos accruals, em virtude de sua natureza normal do curso das ações de uma empresa, auxilia na explicação da persistência dos lucros.

Para a variável de maior interesse dessa pesquisa, referente aos ACCD, o sinal positivo encontrado para esta amostra contraria a ideia de que essa parcela prejudica a persistência dos lucros em virtude do gerenciamento de resultados, conforme esperado. Assim, considerado o resultado obtido para a variável ACCD, rejeita-se a $\mathrm{H} 1$ desta pesquisa.

A contribuição da variável ACCD na persistência dos lucros parece estar de acordo com Arya, Glover e Sunder (2003), que apontam o gerenciamento de resultados como uma atribuição natural dos gestores, tendo em vista que estes possuem capacidade para mitigar as variações transitórias sobre o desempenho das empresas, reportando uma informação ao mercado que apresenta menos incertezas, fato apontado por Graham, Harvey e Rajgopal (2005) como benéfico aos usuários externos. 
Ainda de acordo com Arya, Glover e Sunder (2003), medidas de gerenciamento de resultados não devem ser vistas como um mal absoluto; dentro de alguns limites, elas podem ser benéficas, portanto, para estes autores, no lugar de tentar eliminar as práticas de gerenciamento de resultados, seria mais útil que as pesquisas buscassem investigar como a contabilidade pode agregar os accruals gerenciados. O trabalho de Silva et al. (2018) segue exatamente essa ideia e verifica que as empresas brasileiras não descontinuam suas operações visando modificar os resultados arbitrariamente, mas sim, as fazem no intuito de apresentar da melhor forma a realidade da entidade nesse quesito.

Esse entendimento está de acordo com a perspectiva informacional, relatada por Paulo (2007), na qual os gestores gerenciam resultados sem propósitos escusos, mas sim com a intenção de melhorar a informação reportada. O fato também é corroborado por Scott (2003), ao explicar que, nessa perspectiva, práticas de gerenciamento de resultados podem ser benéficas aos usuários externos ao complementar informações pouco relevantes.

Na comparação dos coeficientes das variáveis ACCD e ACCND, tem-se que estes estão em linha com o que foi disposto por Xie (2001), ao apontar que a persistência dos ACCD é menor quando comparada aos ACCND, justamente porque essa parcela é não esperada. Esse mesmo resultado foi identificado na pesquisa nacional de Cupertino (2010).

Com a inclusão das variáveis dummies, os resultados encontrados para o modelo 2 foram:

Tabela 5 - Resultados do modelo 2 (com dummies)

\begin{tabular}{|c|c|c|c|c|}
\hline \multicolumn{5}{|c|}{ Painel A } \\
\hline $\mathrm{L}_{\mathrm{t}}$ & Coeficiente & Erro Padrão & Razão-t & p-valor \\
\hline Constante & 0,0719414 & 0,0101345 & 7,10 & 0,000 \\
\hline $\mathrm{FCO}_{\mathrm{t}-1}$ & 0,4116097 & 0,0684079 & 6,01 & 0,000 \\
\hline $\mathrm{ACCND}_{\mathrm{t}-1}$ & 0,7623087 & 0,1629087 & 4,68 & 0,000 \\
\hline $\mathrm{ACCD}_{\mathrm{t}-1}$ & 0,4140663 & 0,0800659 & 5,17 & 0,000 \\
\hline DIFRS & $-0,0302042$ & 0,0140838 & $-2,14$ & 0,034 \\
\hline $\mathrm{D}_{\text {IFRS }} \times \mathrm{FCO}_{\mathrm{t}-1}$ & $-0,1165022$ & 0,1012780 & $-1,15$ & 0,253 \\
\hline $\mathrm{D}_{\text {IFRS }} \times \mathrm{ACCND}_{\mathrm{t}-1}$ & $-0,2353958$ & 0,2190649 & $-1,07$ & 0,285 \\
\hline DIFRS $_{\text {X }} \mathrm{ACCD}_{\mathrm{t}-1}$ & $-0,1056219$ & 0,1008827 & $-1,05$ & 0,298 \\
\hline \multicolumn{5}{|c|}{ Painel B } \\
\hline $\mathrm{R}^{2}$ Geral & 0,3699 & \multicolumn{2}{|c|}{$\mathrm{F}$} & 16,50 \\
\hline $\mathrm{P}$-valor $(\mathrm{F})$ & 0,0000 & \multicolumn{2}{|c|}{ Jarque-Bera } & 0,0000 \\
\hline Breusch-Pagan & 0,0000 & \multicolumn{2}{|c|}{ Chow } & 0,0000 \\
\hline Hausman & 0,0000 & \multicolumn{2}{|c|}{ LM Breusch-Pagan } & 1,0000 \\
\hline Wooldridge & 0,0000 & \multicolumn{2}{|c|}{ Maior VIF } & 6,28 \\
\hline
\end{tabular}

Fonte: elaboração própria. 
O modelo 2, com as dummies inclusas, mantém a significância estatística a 99\% de confiança e seu poder explicativo é reduzido minimamente, em cerca de $2 \%$. Além disso, as variáveis independentes continuam a ser significativas e sustentam o sinal apresentado anteriormente.

O coeficiente da variável ACCND é inflado em cerca de 0,30 unidades, mas os coeficientes das variáveis FCO e ACCD, esta última, a mais relevante para esta pesquisa, continuam praticamente os mesmos.

Nenhuma das dummies multiplicativas atreladas a cada componente do lucro apresentou significância estatística. Portanto, de acordo com os resultados desse estudo, a adoção das IFRS não gerou qualquer tipo de reflexo na persistência dos lucros, independentemente da parcela observada. Esse resultado é contrário ao que foi exposto por Domingos, Lima e Ponte (2013), mas cabe ressaltar que, em tal pesquisa, as autoras concluem que nem todas as contas observadas foram diagnosticadas como gerenciadas (no caso, por suavização), cabendo a avaliação subjetiva de cada uma delas a explicação para tal diferença.

Em relação aos fluxos de caixa, cabe destacar que somente no período pós-IFRS a DFC passou a ser obrigatória para as empresas de capital aberto. Faz sentido crer que a informação mais transparente desse período fosse de melhor qualidade, fato não corroborado por esta pesquisa.

Isso pode decorrer do fato da presente pesquisa manter o mesmo padrão para todas as observações, não coletando os fluxos de caixa diretamente da DFC em momento algum. Assim, os fluxos de caixa de 2010 a 2017 foram, tal qual os referentes ao período 2000-2007, obtidos pela diferença entre o EBIT e os accruals totais que, por sua vez, haviam sido estimados pelo Balanço Patrimonial.

Já para a variável ACCND, a indiferença da qualidade informacional dessa medida no que tange à persistência dos lucros perante à adoção das IFRS parece ser contrária, por exemplo, ao resultado encontrado por Boina e Macedo (2018), quando esses verificaram um sinal negativo no período pré-IFRS para essa variável na previsão de fluxos de caixa futuros, enquanto que, no período pós-IFRS, o sinal passava a ser positivo.

Embora a variável explicada do estudo mencionado não seja a mesma que a observada na presente pesquisa, é válido mencionar esse distinto resultado, ainda que não seja possível fazer comparações generalizadas em qualquer aspecto.

E, no que diz respeito ao impacto da adoção das IFRS na persistência dos lucros diante 
dos accruals discricionários, a insignificância estatística da variável dummy multiplicativa em questão sugere que, embora estudos anteriores tenham identificado reflexos da adoção das IFRS no Brasil nos accruals discricionários em termos de volume, a exemplo de Joia e Nakao (2014) e Boina e Macedo (2018), essa alteração não é capaz de influenciar a persistência dos lucros diante dessa parcela. Destarte, a $\mathrm{H} 2$ desta pesquisa foi rejeitada.

Conforme mencionado na metodologia, são apresentadas a seguir, adicionalmente, as análises em torno dos accruals discricionários negativos e dos accruals discricionários extremos. De forma preliminar às análises dos modelos 3 e 4, as Tabelas 6 e 7, a seguir, denotam o comportamento das variáveis em questão em termos descritivos.

Tabela 6 - Composição dos ACCD Negativos

\begin{tabular}{l|c|c}
\hline \multicolumn{1}{c|}{ Delineamento } & Total & Percentual de casos \\
\hline Observações que apresentaram ACCD negativos & 596 & $49,67 \%$ \\
\hline $\begin{array}{l}\text { Empresas que apresentaram ao menos uma vez ACCD } \\
\text { negativos }\end{array}$ & 99 & $99 \%$ \\
\hline $\begin{array}{l}\text { Empresas que apresentaram ACCD negativos em todos } \\
\text { os períodos }\end{array}$ & 0 & $0 \%$ \\
\hline ACCD negativos no período pré-IFRS & 262 & $43,96 \%$ \\
\hline ACCD negativos no período pós-IFRS & 334 & $56,04 \%$ \\
\hline
\end{tabular}

Fonte: elaboração própria.

Tabela 7 - Composição dos ACCD Extremos

\begin{tabular}{l|c|c}
\hline \multicolumn{1}{c|}{ Delineamento } & Total & Percentual de casos \\
\hline $\begin{array}{l}\text { Empresas que apresentaram ao menos uma vez ACCD } \\
\text { extremos }\end{array}$ & 83 & $83 \%$ \\
\hline $\begin{array}{l}\text { Empresas que apresentaram ACCD extremos em todos os } \\
\text { períodos }\end{array}$ & 0 & $0 \%$ \\
\hline ACCD extremos no período pré-IFRS & 158 & $52,67 \%$ \\
\hline ACCD extremos no período pós-IFRS & 142 & $47,33 \%$ \\
\hline
\end{tabular}

Fonte: elaboração própria.

Nota-se que nenhuma empresa apresentou ACCD negativos ou ACCD extremos em todos os exercícios e que a grande maioria das empresas apresentou, ao menos uma vez, ACCD negativos e ACCD extremos. Esse fato mitiga um possível viés das análises em virtude de os dados estarem sendo influenciados por poucas empresas da amostra.

Além disso, os ACCD negativos representam praticamente a metade dos ACCD como um todo, isolando, de igual forma, o risco de as análises estarem sendo influenciadas por uma supremacia de um ou outro sinal dessa variável. Por fim, em ambos os casos, não há grandes discrepâncias no que diz respeito à relação dos períodos pré-IFRS e pós-IFRS.

Destarte, seguem os resultados obtidos frente ao modelo 3 da pesquisa e suas 
respectivas inferências.

Tabela 8 - Resultados do modelo 3

\begin{tabular}{|c|c|c|c|c|}
\hline \multicolumn{5}{|c|}{ Painel A } \\
\hline $\mathrm{L}_{\mathrm{t}}$ & Coeficiente & Erro Padrão & Razão-t & p-valor \\
\hline Constante & 0,0460507 & 0,0074825 & 6,15 & 0,000 \\
\hline $\mathrm{L}_{\mathrm{t}-1}$ & 0,4897971 & 0,0682702 & 7,17 & 0,000 \\
\hline $\mathrm{D}_{\text {IFRS }}$ & $-0,0138018$ & 0,0131742 & $-1,05$ & 0,297 \\
\hline DIFRS $\times L_{t-1}$ & $-0,1735550$ & 0,1353078 & $-1,28$ & 0,203 \\
\hline $\mathrm{D}_{\text {ACCDNEG }}$ & 0,0170476 & 0,0109363 & 1,56 & 0,122 \\
\hline $\mathrm{D}_{\mathrm{ACCDNEG}} \times \mathrm{L}_{\mathrm{t}-1}$ & $-0,1322851$ & 0,0758229 & $-1,74$ & 0,084 \\
\hline DIFRS $_{\text {X D }}$ ACCDNEG & $-0,0158125$ & 0,0143054 & $-1,11$ & 0,272 \\
\hline $\mathrm{D}_{\text {IFRS }} \times \mathrm{D}_{\text {ACCDNEG }} \times \mathrm{L}_{\mathrm{t}-1}$ & 0,1171099 & 0,1210144 & 0,97 & 0,336 \\
\hline \multicolumn{5}{|c|}{ Painel B } \\
\hline $\mathrm{R}^{2}$ Geral & 0,3748 & \multicolumn{2}{|c|}{$\mathrm{F}$} & 18,01 \\
\hline $\mathrm{P}$-valor $(\mathrm{F})$ & 0,0000 & \multicolumn{2}{|c|}{ Jarque-Bera } & 0,0000 \\
\hline Breusch-Pagan & 0,0000 & \multicolumn{2}{|c|}{ Chow } & 0,0000 \\
\hline Hausman & 0,0000 & \multicolumn{2}{|c|}{ LM Breusch-Pagan } & 1,0000 \\
\hline Wooldridge & 0,0000 & \multicolumn{2}{|c|}{ Maior VIF } & 5,16 \\
\hline
\end{tabular}

Fonte: elaboração própria.

Nota-se a significância do modelo como um todo, dado um p-valor (F) de 0,0000 e um poder explicativo de aproximadamente $37,5 \%$. A variável $\mathrm{L}_{\mathrm{t}-1}$ também apresenta significância estatística e suporta um coeficiente superior em aproximadamente 0,7 unidades ao obtido no modelo 1 com as dummies, que não considerava o impacto dos ACCD negativos.

A variável dummy que interagiu os ACCD negativos com o lucro defasado e a variável dummy que interagiu os ACCD negativos e a adoção das IFRS com o lucro defasado não apresentaram significância estatística considerando um nível de confiança de 95\%, haja vista seus respectivos p-valores de 0,084 e 0,336 .

Portanto, embora Paulo (2007) tivesse apontado as diferenças entre os sinais da variável ACCD em termos de objetivos, de acordo com a amostra obtida na presente pesquisa, é possível inferir que tal sinal não interfere na relação do lucro defasado e o lucro corrente, seja essa verificação feita com ou sem os efeitos da adoção das IFRS no Brasil.

E, quanto ao gerenciamento de resultados via ACCD de alta intensidade, tem-se que: 
Tabela 9 - Resultados do modelo 4

\begin{tabular}{|c|c|c|c|c|}
\hline \multicolumn{5}{|c|}{ Painel A } \\
\hline $\mathrm{L}_{\mathrm{t}}$ & Coeficiente & Erro Padrão & Razão-t & p-valor \\
\hline Constante & 0,0438185 & 0,0048212 & 9,09 & 0,000 \\
\hline $\mathrm{L}_{\mathrm{t}-1}$ & 0,5188817 & 0,0491403 & 10,56 & 0,000 \\
\hline DIFRS & $-0,0208469$ & 0,0083805 & $-2,49$ & 0,015 \\
\hline $\mathrm{D}_{\text {IFRS }} \times \mathrm{L}_{\mathrm{t}-1}$ & $-0,0188733$ & 0,0866862 & $-0,22$ & 0,828 \\
\hline $\mathrm{D}_{\text {Alto GR }}$ & 0,0341181 & 0,0180447 & 1,89 & 0,062 \\
\hline $\mathrm{D}_{\text {Alto }}$ GR $\times \mathrm{L}_{\mathrm{t}-1}$ & $-0,2570229$ & 0,1322030 & $-1,94$ & 0,055 \\
\hline DIFRS $x$ D Alto GR & $-0,0252469$ & 0,0217229 & $-1,16$ & 0,248 \\
\hline 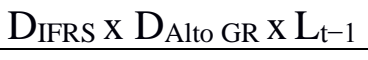 & $-0,1280017$ & 0,1721898 & $-0,74$ & 0,459 \\
\hline \multicolumn{5}{|c|}{ Painel B } \\
\hline $\mathrm{R}^{2}$ Geral & 0,3907 & \multicolumn{2}{|c|}{$\mathrm{F}$} & 30,06 \\
\hline $\mathrm{P}$-valor $(\mathrm{F})$ & 0,0000 & \multicolumn{2}{|c|}{ Jarque-Bera } & 0,0000 \\
\hline Breusch-Pagan & 0,0000 & \multicolumn{2}{|c|}{ Chow } & 0,0000 \\
\hline Hausman & 0,0000 & \multicolumn{2}{|c|}{ LM Breusch-Pagan } & 1,0000 \\
\hline Wooldridge & 0,0000 & \multicolumn{2}{|c|}{ Maior VIF } & 3,44 \\
\hline
\end{tabular}

Fonte: elaboração própria.

O modelo 4 também apresenta significância estatística com um nível de 95\% de confiança, haja vista seu p-valor (F) de 0,0000. O poder explicativo fica em torno de $39 \%$. De igual forma, a variável $\mathrm{L}_{\mathrm{t}-1}$ mantém sua significância estatística e apresenta um coeficiente maior quando comparado ao seu equivalente no modelo 1 (avanço de cerca de 0,10 unidades).

Consoante aos p-valores 0,055 e 0,459, constata-se a insignificância estatística das variáveis que interagem os ACCD extremos com os lucros correntes e as que as fazem em interação conjunta à adoção das IFRS. Com esse resultado, há uma sugestão de que, diante dessa amostra, ainda que ocorram medidas de gerenciamento de resultados em larga escala, estas não são capazes de impactar a persistência dos lucros e isso se repete quando é observada tal relação considerando a adoção das IFRS no mercado brasileiro.

Para fins de constatação, os accruals extremos foram verificados diante do decil superior no lugar do quartil superior e, de igual forma, os resultados seguiram as mesmas tendências.

\section{CONSIDERAÇÕES FINAIS}

Como primeiro passo para o cumprimento do objetivo geral da pesquisa, foi verificada a persistência dos lucros das empresas listadas na B3, considerando os efeitos da adoção das IFRS no Brasil. Foi constatada a persistência dos lucros para a amostra selecionada e 
identificado que a adoção das IFRS não gera qualquer tipo de reflexo nessa relação.

Porém, diante do objetivo geral da pesquisa de analisar especificamente o impacto dos accruals discricionários na persistência dos lucros, dada a possibilidade de gerenciamento de resultados nessa medida, foi necessário decompor o lucro defasado em suas três parcelas, a saber: fluxo de caixa, acumulações não discricionárias e acumulações discricionárias.

Todas as parcelas do lucro apresentaram influência positiva na explicação dos lucros correntes e, ademais, nenhuma das parcelas teve tal relação impactada diante da adoção das IFRS no Brasil.

Conquanto o foco do estudo fosse a variável referente aos accruals discricionários, o resultado obtido, diferentemente do esperado, foi de que essa parcela estaria contribuindo para a explicação dos lucros correntes. Isso contraria a teoria acerca das medidas de gerenciamento de resultados, mas parece sugerir que os gestores estão gerenciando parte dos accruals não com objetivos pessoais, mas sim em busca de uma informação de melhor qualidade sobre o desempenho das empresas.

As contribuições dessa pesquisa auxiliam os estudos sobre gerenciamento de resultados ao apontar que tais práticas, representadas aqui pelos accruals discricionários, podem contribuir, em certos casos, na qualidade da informação contábil reportada ao mercado. Além disso, como diferencial, esta pesquisa sugere que a adoção das IFRS não representa qualquer tipo de avanço ou retrocesso na persistência dos lucros, muito embora altere o volume de accruals discricionários conforme apontamento feito em trabalhos anteriores.

Cabe destacar que, conforme relatado por alguns autores, em se tratando de accruals discricionários, há uma ampla gama de modelos aplicáveis para suas estimações. Esse fato, por si só, já representa uma limitação para esta pesquisa e para todas as outras correlatas, tendo em vista que, com estimações distintas, resultados distintos serão obtidos. Outra limitação diz respeito à amostra selecionada, que exigiu dados disponíveis das empresas durante um grande intervalo (2000-2017). Isso pode remeter a uma amostra que não represente a realidade do mercado como um todo, mas sim de empresas mais longevas.

Como sugestões para pesquisas posteriores, propõe-se (I) a verificação da persistência de cada parcela do lucro diante de sua parcela defasada, visando identificar de forma analítica a relação dessas variáveis; e (II) a segregação das empresas observadas de acordo com os setores de suas respectivas atividades, permitindo, assim, identificar se o comportamento dos 
accruals discricionários apresenta alguma peculiaridade em um determinado setor diante de características como sazonalidade, regulamentação e gama de concorrência.

\section{REFERÊNCIAS}

AHMED, K.; CHALMERS, K.; KHLIF, H. A Meta-Analysis of IFRS Adoption Effects. The International Journal of Accouting, v. 48, p. 173-217, 2013.

ALMEIDA, J. E. F. Qualidade da informação contábil em ambientes competitivos. Tese (Doutorado em Controladoria e Contabilidade: Contabilidade) - Faculdade de Economia, Administração e Contabilidade, Universidade de São Paulo, São Paulo, 2010.

ALMEIDA, J. E. F.; LOPES, A. B.; CORRAR, L. J. Gerenciamento de resultados para sustentar a expectativa do mercado de capitais: impactos no índice market-to-book. Advances in Scientific and Applied Accounting, v. 4, n. 1, p. 44-62, 2011.

ARYA, A.; GLOVER, S.; SUNDER, S. Are Unmanaged Earnings Always Better for Shareholders? Accounting Horizons, v. 17, Supplement, p. 111-116, 2003.

BARTH, M. E.; LANDSMAN, W. R.; LANG, M. H. International Accounting Standards and accounting quality. Journal of Accounting Research, v. 46, n. 3, p. 467-498, 2008.

BOINA, T. M.; MACEDO, M. A. S. Capacidade preditiva de accruals antes e após as IFRS no mercado acionário brasileiro. Revista Contabilidade \& Finanças, v. 29, n. 78, p. 375$389,2018$.

BRASIL. Lei 11.638 , de 28 de dezembro de 2007. Altera e revoga dispositivos da Lei no 6.404, de 15 de dezembro de 1976, e da Lei no 6.385, de 7 de dezembro de 1976, e estende às sociedades de grande porte disposições relativas à elaboração e divulgação de demonstrações financeiras. Disponível em: <http://www.planalto.gov.br/ccivil_03/_ato2007-2010/2007/lei/111638.htm>. Acesso em: 01 nov. 2018.

CALLAO, J.; JARNE, J. I. "Have IFRS Affected Earnings Management in the European Union?" Accounting in Europe, v. 7, n. 2, p. 159-189, 2010.

CARDOSO, R. L.; SOUZA, F. S. R. N.; DANTAS, M. M. Impactos da adoção do IFRS na acumulação discricionária e na pesquisa em gerenciamento de resultados no brasil. Revista Universo Contábil, v. 11, n. 2, p. 65-84, 2015. 
CHAN, K. H.; LIN, K. Z.; MO, P. L. L. Will a departure from tax-based accounting encourage tax noncompliance? Archival evidence from a transition economy. Journal of Accounting and Economics, v. 50, n. 1, p. 58-73, 2010.

CHEN, H.; TANG, Q.; JIANG, Y.; LIN, Z. The role of International Financial Reporting Standards in accounting quality: Evidence from the European Union. Journal of International Financial Management and Accounting, v. 21, n. 3, p. 220-278, 2010.

CONSONI, S.; COLAUTO, R.; LIMA, G. A. S. F. A divulgação voluntária e o gerenciamento de resultados contábeis: evidências no mercado de capitais brasileiro. Revista Contabilidade \& Finanças, v. 28, n. 74, p. 249-263, 2017. DOI 10.1590/1808057x201703360.

CORRAR, L. J.; PAULO, E.; DIAS FILHO, J. M. Análise Multivariada: para os cursos de Administração, Contábeis e Economia. São Paulo: Atlas, 2007. 642p.

CUPERTINO, C. M. Anomalia dos accruals no mercado brasileiro de capitais. Tese (Doutorado em Engenharia de Produção). Universidade Federal de Santa Catarina, 2010.

DASKE, H. Economic benefits of adopting IFRS or US-GAAP: have the expected cost of equity capital really decreased? Journal of Business Finance and Accounting, v. 33, p. 329373, 2006.

DECHOW, P. M.; DICHEV, I. D. The quality of accruals and earnings: the role of accrual estimation errors. The Accounting Review, v. 77, p. 35-59, 2002.

DECHOW, P. M.; GE, W. The persistence of earnings and cash flows and the role of special items: Implications for the accrual anomaly. Review of Accounting studies, v. 11, n. 2-3, p. 253-296, 2006.

DECHOW, P. M.; SCHRAND, C. M. Earnings quality. New York, NY: Research of Foundation of CFA Institute. 2004. Disponível em <http://www.cfapubs.org/doi/pdf/10.2470/rf.v2004.n3.3927>. Acesso em: 17 jul. 2018.

DECHOW, P. M.; GE, W.; SCHRAND, C. M. Understanding earnings quality: A review of the proxies, their determinants and their consequences. Journal of Accounting and Economics, v. 50, n. 2, p. 344-401, 2010.

DECHOW, P. M.; SLOAN, R.; SWEENEY, A. Detecting Earnings Managements. The Accounting Review, v. 70, n. 2, p. 193-225, 1995. 
DICHEV, I. D.; GRAHAM, J. R.; HARVEY, C. R.; RAJGOPAL, S. Earnings quality: Evidence from the field. Journal of Accounting and Economics, v. 56, n. 2-3, p. 1-33, 2013.

DICHEV, I. D.; GRAHAM, J. R.; HARVEY, C. R.; RAJGOPAL, S. The Misrepresentation of Earnings. SSRN Electronic Journal, p. 1-23, 2014. doi:10.2139/ssrn.2376408

DRUKKER, D. M. Testing for serial correlation in linear panel-data models. The Stata Journal, v. 3, n. 2, p. 168- 177, 2003.

DOMINGOS, S. R. M.; LIMA, S. M.; PONTE, V. M. R. Income Smoothing: um estudo após a adoção do IFRS no Brasil. Contextus - Revista Contemporânea de Economia e Gestão, v. 11, n. 2, 2013.

FÁVERO, L. P.; BELFIORE, P.; SILVA, F. L.; CHAN, B. L. Análise de dados: modelagem multivariada para tomada de decisões. Rio de Janeiro: Elsevier, 2009.

FÉ JÚNIOR, A. L. D.; NAKAO, S. H.; RIBEIRO, M. S. Reações do mercado acionário na primeira divulgação financeira em IFRS do setor bancário brasileiro: um estudo de evento. Contextus - Revista Contemporânea de Economia e Gestão, v. 13, n. 3, p. 81-110, 2015.

GRAHAM, J. R.; HARVEY, C. R.; RAJGOPAL, S. The economic implications of corporate financial reporting. Journal of Accounting and Economics, v. 40, n. 1-3, p. 3-73, 2005.

GRECCO, M. C. P.; GERON, C. M. S.; GRECCO, G. B.; LIMA, J. P. C. The effect of IFRS on earnings management in Brazilian non-financial public companies. Emerging Markets Review, v. 21, p. 42-66, 2014.

GREENE, W. H. Econometric Analysis. 5. ed. New Jersey: Prentice Hall, 2003.

GUJARATI, D. N.; PORTER, D. C. Econometria básica. 5. ed. Porto Alegre: AMGH, 2011. 924p.

HEALY, P. M.; WAHLEN, J. M. A Review of the Earnings Management Literature and Its Implications for Standard Setting. Accounting Horizons, v. 13, n. 4, p. 365-383, 1999.

HENDRIKSEN, E. S.; VAN BREDA, M. F. Teoria da Contabilidade. 5. ed. São Paulo: Atlas, 2009.

HOECHLE, D. Robust Standard Errors for Panel Regressions with Cross-Sectional Dependence. The Stata Journal, v. 7, n. 3, p. 281-312, 2007. 
INTERNATIONAL ACCOUNTING STANDARDS BOARD (IASB). The Conceptual Framework for Financial Reporting. September 2010. Disponível em: <http://eifrs.ifrs.org>. Acesso em: 25 mai. 2018.

JOIA, R. M.; NAKAO, S. H. Adopción de IFRS y gerenciamento de resultado em las empresas brasileñas de capital abierto. Revista de Educação e Pesquisa em Contabilidade, v. 8, n. 1, p. 22-38, 2014.

KLANN, R. C.; BEUREN, I. M. Gerenciamento de Resultados: análise comparativa de empresas brasileiras e inglesas antes e após a adoção das IFRSs. In: Encontro Nacional da Associação Nacional de Pós-Graduação e Pesquisa em Administração. 36., 2012, Rio de Janeiro. Anais... Rio de Janeiro, ANPAD, 2012.

KOTHARI, S. P. Capital Markets Research in Accounting. Journal of Accounting and Economics, v. 31, p. 105-231, 2001.

KOLOZSVARI, A. C.; MACEDO, M. A. S. Análise da Influência da Presença da Suavização de Resultados sobre a Persistência dos Lucros no Mercado Brasileiro. Revista Contabilidade \& Finanças, v. 27, n. 72, p. 306-319, 2016.

KOLOZSVARI, A. C.; MACEDO, M. A. S. A Relação entre Suavização, Persistência e a Adoção dos IFRS. Revista Brasileira de Finanças, v. 16, n. 2, p. 251-284, 2018.

LEAL, L. T. Y.; GIRÃO, L. F. A. P.; LUCENA, W. G. L.; MARTINS, V. G. Persistence, value relevance, and accruals quality in extreme earnings and cash flow situations. RAM, Revista de Administração da Mackenzie, v. 18, n. 3, p. 203-231, 2017.

LEUZ, C.; NANDA, D.; WYSOCKI, P. D. Earnings management and investor protection: An international comparison. Journal of Financial Economics, v. 69, n. 3, p. 505-527, 2003.

LEV, B. Some economic determinants of time-series properties of earnings. Journal of Accounting and Economics, v. 5, p. 31-48, 1983.

LOPES, A. B.; MARTINS, E. Teoria da Contabilidade: uma nova abordagem. São Paulo: Atlas, 2005.

MARTINEZ, A. L. Detectando Earnings Management no Brasil: estimando os accruals discricionários. Revista de Contabilidade \& Finanças, v. 19, n. 46, p. 7-17, 2008. 
MARTINS, G. de A.; THEÓPHILO, C. R. Metodologia da Investigação Científica para Ciências Sociais Aplicadas. 2 ed. São Paulo: Atlas, 2009. 247p.

NISSIM, D.; PENMAN, S. Ratio analysis and equity valuation: from research to practice. Review of Accounting Studies, v. 6, p. 109-154, 2001.

PAULO, E. Manipulação das informações contábeis: uma análise teórica e empírica sobre os modelos operacionais de detecção de gerenciamento de resultados. Tese (Doutorado em Ciências Contábeis). Faculdade de Economia, Administração e Contabilidade da Universidade de São Paulo, 2007.

PAUlO, E.; CAVAlCANTE, P. R. N.; MELO, I. I. S. L. Qualidade das informações contábeis na oferta pública de ações e debêntures pelas companhias abertas brasileiras. Brazilian Business Review, v. 9, n. 1, p. 1-26, 2012.

PALEPU, K. G.; HEALY, P. M.; BERNARD, V. L. Business Analysis Evaluation: Using Financial Statements. 3. ed. Ohio: Thomson Learning, 2004.

PRATHER-KINSEY, J.; SHELTON, S. W. IAS versus U.S. GAAP: Assessing the quality of financial reporting in South Africa, the United Kingdom, and the United States. Advances in International Accounting, v. 18, p. 153-16, 2005.

ROGERS, W. Regression Standard Errors in Clustered Samples. Stata Technical Bulletin Reprints. v. 3., p. 88-94, 1994.

SCOTT, W. R. Financial Accounting Theory. 3rd. Ed. Toronto: Prentice Hall, 2003.

SILVA, A. H. C.; SILVA, E. G. R. Análise das demonstrações de resultado abrangente após a implementação do IFRS no Brasil. Contextus - Revista Contemporânea de Economia e Gestão, v. 13, n. 1, 2015.

SILVA, A. H. C.; SILVA, C. E. V.; SANCONVSCHI, M.; BORBA, J. A. Analysis of discontinued operations in Brazil after IFRS 5 adoption. Contextus - Revista Contemporânea de economia e gestão, v. 16, n. 3, p. 8-39, 2018.

SINCERRE, B. P.; SAMPAIO J. O.; FAMÁ, R.; SANTOS, J. O. Emissão de Dívida e Gerenciamento de Resultados. Revista de Contabilidade \& Finanças, v. 27, n. 72, p. 291$305,2016$. 
SLOAN, R. G. Do stock prices fully reflect information in accruals and cash flows about future earnings? The Accounting Review, v. 17, n. 3, p. 289-315, 1996.

TAKAMATSU, R. T.; FÁVERO, L. P. Accruals, Persistence of Profits and Stock Returns in Brazilian Public Companies. Modern Economy, v. 4, n. 2, p. 109-118, 2013.

VAN TENDELOO, B.; VANSTRAELEN, A. Earnings management under German GAAP versus IFRS. European Accounting Review, v. 14, n. 1, p. 155-180, 2005.

XIE, H. The Mispricing of Abnormal Accruals. The Accounting Review, v. 76, n. 3, p. 357373, 2001. 